\title{
EDITORIAL IMPRESSIONS: FEELINGS OF HYBRIDITY
}

\author{
ART LEETE
}

Hybridity is the other side of transparency. Let's start the discussion from the legacy of the Enlightenment. If somebody searches for clarity, this is a reasonable starting point. In his First Discourse, written in 1750, Jean-Jacques Rousseau claimed that in an uncivilised state, man appears natural and transparent.

The honest man is an athlete who loves to wrestle stark naked; he scorns all those vile trappings, which prevent the exertion of his strength, and were, for the most part, invented only to conceal some deformity. Before art moulded our behavior, and taught our passions to speak an artificial language, our morals were rude but natural; and the different ways in which we behaved proclaimed at the first glance the difference of our dispositions. Human nature was not at bottom better then than now; but men found their security in the ease with which they could see through one another, and this advantage, of which we no longer feel the value, prevented their having many vices. (Rousseau 1997: 6)

Similarly to the way in which clothing conceals the form of one's body, appropriated ideas and habits make human minds and actions hybrid. According to Rousseau, arts and sciences change our social interface completely. Today, the notion of hybridity is used when referring to the conception of new cultural phenomena that emerge in the contact zones (Ashcroft et al. 2007: 108). The experience of hybridity becomes more meaningful or apparent when rather distant and different ideas and practices are brought together. We may even not notice it when familiar traditions are mixed. In this sense, hybridity is produced by distinction, not variety.

Homi K. Bhabha (1994) opposes cultural difference to diversity. Cultural diversity is an "object of empirical knowledge", involving multiculturalism, intertextuality and exchange. But difference functions as a tool for constructing identity that becomes significant at the boundaries of cultures. (Ibid.: 34)

In hybrid cultural processes, the dominant agents pressure interdependent subjectivities, stimulating mimicry and producing ambivalence. Cultural distinctiveness becomes vague, because it appears in paradoxical and blurred areas. Hybridity has the potential to empower cultural processes in these unbalanced culture spaces. (Young 1995: 21; Ashcroft et al. 2007: 108)

* This essay is based on research supported by the Estonian Kindred Peoples Programme, project No. 782, and the University of Tartu, project PHVKU19913. 
Cultural diversity may produce phenomena similar to those created by hybridity, but these processes emerge from diverse contexts (Bhabha 1994: 38). Hybridity is "the act of living on borderlands" and is related to "the indeterminate temporality of inbetween, that needs to be engaged in creating the conditions through which 'newness comes into the world"' (ibid.: 227-228).

Hybridity is regarded as a cross-cultural unbalanced exchange of objects and experience in a post-colonial context. The concept also facilitates understanding of cultural processes in terms of syncretism, synergy and transculturation as a result of post-colonial dependence. But hybridity can also be comprehended without this notion of hierarchy between agents of exchange. (Young 1995: 21-22; Ashcroft et al. 2007: 109)

As the concept involves motivation of development, analysis of hybrid processes tends to overlook any colonial ambivalence behind social change. Understanding of hybridity enables us to see local social scenes as dynamic. It challenges colonial discourse about permanently fixed local subjects, identities and traditions. (Mizutani 2008: 2, 9)

In communities that share "histories of deprivation and discrimination, the exchange of values, meanings and priorities may not always be collaborative and dialogical, but may be profoundly antagonistic, conflictual and even incommensurable" (Bhabha 1994: 2).

A challenge for the concept relies in connecting it to particular local distinctions: as an abstract, globalised concept, hybridity de-contextualises actual cultural settings. (Young 1995: 22; Ashcroft et al. 2007: 109, 111; Mizutani 2008: 16) Hybridity may appear to be a purely textual endeavour that explains overall processes but is not applicable for an analysis of specific cultural conditions.

Hybridisation can be organic, executed by people themselves, but also politically motivated and administratively implemented, aiming to disrupt balance in indigenous communities. Hybridity emerges in situations of conflict, separation, subversion, and contestation. Although stimulated purposefully, hybrid cultural processes often have unforeseen results. In the course of these processes, colonial domination may be reversed, transformed into moments of challenge and resistance and producing assertions of indigenous legitimacy. But one needs to be cautious when articulating this autochthonous aspect of hybridity. Such discussions could still end up repeating colonial discourse from the past. (Bhabha 1994: 156; Young 1995: 21-22; Ashcroft et al. 2007: 110)

The concept of hybridity can thus be connected to the understanding of contemporary social and cultural boundaries as symbolic and vague. It enables us to investigate the significance of boundaries in the context of cultural movements and state policies (Eriksen and Jakoubek 2019: 11). Ethnic communities are not homogeneous or organic but penetrated by "transnational and translational sense of the hybridity" (Bhabha 1994: 5). It is easy not to notice the effects of this long-term colonial process because hybridity acts through "the silent repression of native traditions" (ibid.: 154; see also Young 1995: 21-24).

In the autumn of 2014, during the height of the hybrid war in Ukraine, I visited my Komi friends in the Russian North. One evening, we were watching a news program on TV. Two stories were broadcast in a row that suggested alternative truths. The first was about the premiere of a new feature film called Sunstroke ${ }^{1}$ by Russian film director 
Nikita Mikhalkov at a film festival in Belgrade, Serbia. The film features a love story but also human suffering during the Russian Civil War (1918-1920). During an interview with a news channel, Mikhalkov emphasised the inhuman nature of the communist regime, which from its very early days under Lenin tortured and exterminated people for no reason and on an unprecedented scale. The next news story was dedicated to a condemnation of Ukraine for launching a countrywide campaign to demolish statues of Lenin.

After we finished watching these news items, an old Komi lady, my hostess, asked me: "Have you also destroyed some statues of Lenin [in Estonia]?" I said to this nice Komi granny that, indeed, we removed all the statues of Lenin many years ago. "Did they eat a lot of your bread?" asked the lady, visibly upset at this unthinkably savage campaign.

After that I started to think about the way our field partners comprehend particular discourses that surround them. What I perceived as an expression of hybridity, this old lady recognised as a harmonious presentation of indisputable fact. One needs to admit that these alternative facts (two completely opposing facts about Lenin as either an angel or the master of the kingdom of evil) were really well balanced and presented in such a way that the old lady picked the right one (depicting Lenin as a saint and Ukraine as a sinful country) and did not notice the other (about Lenin being a malicious ruler). Both stories also had a larger shared purpose - to confirm the existence of the Russian World ${ }^{2}$ and to blame Ukraine for attempting to exit from this union of nations that has existed from time immemorial.

The Komi have lived under Russian rule for so long (since the 14th century) that it no longer feels like a colonial encounter. Although speaking a language totally different from Russian (Komi belongs to the Finno-Ugric branch of the Uralic language family), the Komi have followed the Russian Orthodox faith for centuries. Therefore, both territorial and religious factors also make them part of the Russian World. As the Komi have not had much choice, they are naturally adapted to the information space to which they belong.

For Bhabha (1994: 33), hybridity involves resistance and adaptation simultaneously. Satoshi Mizutani (2008: 16-17) considers the way in which Bhabha articulates hybridity as a mode of resistance that can occur only as a result of adaptation to a colonial discourse problematic. For Mizutani, this notion of the deconstructive potential of hybridity rather legitimises "the teleological logic of imperial penetration".

I consider that the Komi granny's attitude to politics is penetrated by hybrid discourses. Her attachment to a state-generated understanding of international relations actualises only while she zombifies in front of the TV. (I admit that from her perspective, while not having bad feelings towards Ukraine, I am the brainwashed one in this situation.) I do not talk about these things with her sons. In this friendship, sometimes silence feels like resistance.

'Hybridity' is also a powerful and multifaceted concept of cultural criticism (Young 1995: 24-26; Mizutani 2008: 1, 16). The notion enables simultaneous panoramic and detailed analysis of diverse sentiments about heterogeneous social phenomena. But it does not eliminate mixed feelings concerning ethnographic encounter penetrated concurrently by official propaganda and cultural intimacy. 
The intimate dimension of hybridity was brought to the theoretical scene earlier than it became a tool of post-colonial cultural critique. Mikhail Bakhtin discusses hybridity as a function of language that enables polyphonic messages, or the "ability to be simultaneously the same but different" (Young 1995: 18-19). Bakhtin (1981: 358) approaches hybridity as a concurrently restricted and fragmented way of perception and expression:

What is a hybridization? It is a mixture of two social languages within the limits of a single utterance, an encounter, within the arena of an utterance, between two different linguistic consciousnesses, separated from one another by an epoch, by social differentiation or by some other factor.

Bakhtin maintains that hybridity enables irony to be generated between arguments within a single speech act (Young 1995: 19). Hybridity bridges the disparity between a person's feelings and reflections. Hybridity mitigates the difference, as "there is no formal - compositional and syntactic - boundary between these utterances, styles, languages, belief systems" (Bakhtin 1981: 304-305).

In Bakhtin's approach, "hybridization always involves its concrete social dimension" (Young 1995: 21). In this sense, hybridity encompasses a fusion of ideas and attitudes in particular locations and manifestation of this amalgamation in actual situations. Here I can return to my Komi friends, sons of the granny I referred to earlier. Being hunters, they sometimes use a specific mode of speaking involving culture-bound intentional hybridity. When telling stories, they often mix plots that are simultaneously real and false, animistic and Christian, express both customary independence and compromise with state law.

I see the narrative tradition of the Komi hunters as a dialogic and mimetic arena for negotiating practical experience and animistic attitudes. Hunters talk intentionally about their ideas and deeds as ambivalent, mixing discourses circulating in their community and society in large. One can never be quite sure if the hunters tell the truth or if they lie. But as a Komi friend once said to me, when telling stories, hunters exchange messages that are meant to confuse the audience. Usually this means that they are attempting to trick each other, aiming to create an obscure mood. I suggest that this confusion enables them to actualise hunting beliefs, to make animistic views true. (Leete and Lipin 2015: 81-82; see also Leete and Lipin 2012: 295-298)

In a rather different cultural context, when interpreting a few cases of story-telling in Assam, Ülo Valk (2015: 161) claims that discrepancies between supposedly truthful facts in folk narratives create ambiguity:

The interplay with contradictory factuality in belief narratives hardly convinces an experienced listener or reader that the stories are true. Rather, it undermines and relativizes their veracity and creates a liminal space where the storyworld coalesces with social reality, evoking and conceiving the supernatural, and thus making it real.

This means that a similar connection between narrating and belief is detected in two quite diverse indigenous cultural settings. Perhaps this is just an accident, although it still enables an argument that this relationship between confusion and belief can be non-culture-specific and instead tell us something about a shared human feature. It is very human to engage hybrid discourses. Cultural hybridity existed long before any colonial encounter. Hybridity is a condition of animistic world perception. 
Bakhtin (1981: 344-366) treats hybridity as a dialectical model for cultural interaction. On the one hand hybridity is organic, unconscious and generative, causing fusion. On the other hand it is intentional, antagonistic and divisive, triggering contestation of cultural differences. (See also Young 1995: 20-21)

Insights into cultural situations do not eliminate the claim about unbalanced social encounters. Hybridity appears as simultaneously intimate and fierce, concurrently a genuine condition of culture and a (post)colonial consequence.

Rousseau is just so wrong. In the field, there is no "athlete who loves to wrestle stark naked". Our ethnographic encounter has been delicate, tricky, and full of riddles from the very beginning.

\section{NOTES}

1 The film is based on two books written by Russian Nobel Prize winner Ivan Bunin - Sunstroke ("Solnechnyy udar", 1925) and Damned Days ("Okayannyye dni", 1918-1920).

2 The concept 'Russian World' is used to mean that all areas touched by Russian (but also the Slavic Orthodox religious) culture belong to or are rightfully influenced by Russia. In Tsarist Russia the concept was part of conservative nationalist ideology (the "Orthodoxy, Autocracy, Nationality" doctrine). The idea was revived in the 1990s and has been strongly promoted by the state since 2007. According to this ideology, Serbia also belongs to the Russian World.

\section{REFERENCES}

Ashcroft, Bill; Gareth Griffiths and Helen Tiffin. 2007. Post-Colonial Studies: The Key Concepts. London; New York, NY: Routledge.

Bakhtin, Mikhail M. 1981. The Dialogic Imagination: Four Essays. Slavic Series 1. Austin, TX: University of Texas Press.

Bhabha, Homi K. 1994. The Location of Culture. London, New York, NY: Routledge.

Eriksen, Thomas Hylland and Marek Jakoubek. 2019. Introduction: Ethnic Groups, Boundaries and Beyond. - Ethnic Groups and Boundaries Today: A Legacy of Fifty Years, edited by Thomas Hylland Eriksen and Marek Jakoubek. London; New York, NY: Routledge, 1-19.

Leete, Art and Vladimir Lipin. 2012. Komi Hunting Narratives. - Vernacular Religion in Everyday Life: Expressions of Belief, edited by Marion Bowman and Ülo Valk. London; New York, NY: Routledge, 282-300.

Leete, Art and Vladimir Lipin. 2015. The Concept of Truth in the Komi Hunting Stories. - Acta Borealia 32 (1): 68-84. DOI: https://doi.org/10.1080/08003831.2015.1014265.

Mizutani, Satoshi. 2008. Hybridity and History: A Critical Reflection on Homi K. Bhabha's 'PostHistorical' Thought. - Zinbun 41: 1-19. DOI: https://doi.org/10.14989/134691.

Rousseau, Jean-Jacques. 1997. The Social Contract and Discourses. London; Vermont: J. M. Dent; Charles E. Tuttle.

Valk, Ülo. 2015. Conceiving the Supernatural through Variation in Experience Stories: Assistant Spirits and Were-Tigers in the Belief Narratives of Assam. - Shaman 23 (1-2): 141-164.

Young, Robert J. C. 1995. Colonial Desire: Hybridity in Theory, Culture, and Race. London, New York, NY: Routledge. 